\title{
Titanium Casting Using Commercial Phosphate-bonded Investments with Quick Heating Method
}

\author{
Min YAN $^{1}$ and Hidekazu TAKAHASHI ${ }^{2}$ \\ ${ }^{1}$ Institute of Oral Materials Science, Chung Shan Medical University, 110, Sec. 1 Chien-Kuo N. Road, Taichung 402, Taiwan \\ ${ }^{2}$ Advanced Biomaterials, Department of Restorative Sciences, Division of Oral Health Sciences Graduate School, Tokyo Medi- \\ cal and Dental University, 1-5-45 Yushima, Bunkyo-ku, Tokyo 113-8549, Japan \\ Corresponding author, Min Yan E-mail:yan@csmu.edu.tw
}

Received January 25, 2006/Accepted February 8, 2006

\begin{abstract}
The purpose of this study was to investigate the possible use of quick heating method for titanium casting using two commercial investments (Rematitan Plus and Tancovest). The resulting characteristics of the investments with the quick heating method were as follows: residual thermal expansion at the casting temperature was in the range of 0.39 to $0.64 \%$; green strength and fired strength ranged from 4.4 to $10.3 \mathrm{MPa}$ and from 13.8 to $17.6 \mathrm{MPa}$, respectively. Five full crown titanium castings from each casting condition were obtained using an argon arc melting and gas pressure casting machine. The thickness of cast surface reaction layer was approximately $200 \mu \mathrm{m}$, regardless of heating methods or investments. Further, the heating method did not significantly influence either the accuracy or surface roughness of the titanium castings. These results therefore suggested that these commercial investments for titanium could be used for the quick heating method.
\end{abstract}

Key words: Titanium, Dental investment, Quick heating method

\section{INTRODUCTION}

In recent years, titanium and titanium alloy have been used as dental casting metals ${ }^{1)}$ because of newly developed titanium alloys ${ }^{2,3)}$ and dental casting machines, as well as improved investments. Hightemperature stable refractories such as $\mathrm{MgO}, \mathrm{Al}_{2} \mathrm{O}_{3}$, $\mathrm{CaO}, \mathrm{ZrO}_{2}$, and $\mathrm{ZrSiO}_{4}$ were employed instead of $\mathrm{SiO}_{2}$ to minimize any reaction with molten titanium ${ }^{4-9)}$. Further, investigations were carried out to examine the effect of adding metal powder, metallic oxide, metallic nitride, or metallic carbide to investments to increase thermal expansion ${ }^{10)}$; to date, commercial products using these additions are already available on the market. To control the thickness of surface reaction layer, the reactivity of molten titanium with the mold is reduced with lowered mold temperatures. In terms of casting process, a commercial investment requires a long period of time including one or two hours of bench set time, a two-stage burnout, and further cooling from $200^{\circ} \mathrm{C}$ to room temperature according to the manufacturer's suggestions. In addition, additives of binding materials in investments might cause longer setting times, decrease in strength, as well as decrease in expansion during setting and heating. For these given reasons, the phosphate-bonded investments for titanium are still on the market using conventional long burnout schedules. The whole casting process usually requires three to nine hours.

On the contrary, a quick heating or accelerated casting technique has time-saving and cost-effective advantages. Therefore, several approaches have been introduced to help reduce operating time during the dental casting process. For quick heating, the epochmaking products are gypsum-bonded and phosphatebonded investments. These investments require only 30 minutes for bench setting and an additional 30 minutes for direct heating at 700 or $800^{\circ} \mathrm{C}$. As a result, the total casting process time is reduced to less than one hour. Several researchers have reported that commercial investments for the quick heating method generally show a fast setting reaction, a relatively large setting expansion, and small thermal expansion; the other characteristics of these investments are similar to those of conventional investments ${ }^{11-16)}$. Based on these evaluation results, the castings using the quick heating method are clinically acceptable ${ }^{11-14,17)}$.

Of late, investments for titanium using the quick heating method have been produced commercially. However, only limited studies have evaluated the quick heating method for titanium ${ }^{18,19)}$. In other words, the compressive strength and permeability of these investments in discussion are considered to play a major role in the tolerance for quick heating ${ }^{19)}$, whereby selected commercial silica- and aluminabased investments for titanium casting can be utilized for quick heating ${ }^{18)}$. However, the dimensional accuracy and surface properties of titanium castings have not been discussed.

The purpose of this study was to investigate the possible use of quick heating for titanium casting using commercial phosphate-bonded investments. In addition, the influence of burnout method on the dimensional accuracy and surface properties of cast 
titanium were also investigated.

\section{MATERIALS AND METHODS}

\section{Investments and heating methods}

Two commercial phosphate-bonded investments for titanium (TV for Tancovest and $\mathrm{RT}$ for Rematitan Plus in Table 1) were used. The $\mathrm{L} / \mathrm{P}$ ratio and the special liquid concentration were used according to the manufacturers' recommendations. These investments were then mixed by hand for 15 seconds, followed by a vacuum mixing machine for an additional 30 seconds.

For the conventional heating method (CHM), the specimen was heated at a rate of $7^{\circ} \mathrm{C} / \mathrm{min}$ to $950^{\circ} \mathrm{C}$ (TV) or at a rate of $5^{\circ} \mathrm{C} / \mathrm{min}$ to $1000^{\circ} \mathrm{C}$ (RT) at 40 minutes after the start of mixing, and then cooled according to the manufacturer's suggestions. For the quick heating method (QHM), specimen was directly heated at the elevated temperature as suggested by the manufacturer at 30 minutes after the start of mixing. Temperature was maintained for 30 minutes and then cooled in a preheated oven of $700^{\circ} \mathrm{C}$ and held for 15 minutes. The casting temperatures as suggested by the manufacturer for TV and RT were $500^{\circ} \mathrm{C}$ and $430^{\circ} \mathrm{C}$, respectively.

\section{Setting expansion}

The freshly mixed investment was put into a steel ring (30 $\mathrm{mm}$ in diameter and $40 \mathrm{~mm}$ in length) with a $0.7-\mathrm{mm}$ thick ring liner sheet (Muffelringeinlage, Servo-dental, Hagen, Germany). Dimensional changes during setting were continuously measured up to 120 minutes after the start of mixing with a dial indicator (Mitsutoyo Corporation, Kanagawa, Japan; minimum reading: $0.001 \mathrm{~mm}$ ). The measuring load was approximately $0.002 \mathrm{~N}$. The dimensional change of investment was calculated as a percentage expansion based on the smallest reading of the dial indicator during setting and the final length of the measured specimen. Three measurements were performed for each investment.

\section{Thermal expansion}

Thermal expansion of cylindrical specimens $6 \mathrm{~mm}$ in diameter and $12 \mathrm{~mm}$ in length was measured. A thermal expansion curve of QHM and CHM were obtained by firing specimens with a dilatometer (Dilatometer 5020, Mac Science, Tokyo, Japan) from
30 minutes and 40 minutes after the start of mixing, respectively. CHM specimens were heated from room temperature to $950^{\circ} \mathrm{C}(\mathrm{TV})$ or $1000^{\circ} \mathrm{C}(\mathrm{RT})$ at a heating rate of $7^{\circ} \mathrm{C} / \mathrm{min}$, while those of $\mathrm{QHM}$ were heated at a heating rate of $20^{\circ} \mathrm{C} / \mathrm{min}$. Subsequently, specimens were cooled to $300^{\circ} \mathrm{C}$ at a cooling rate of $20^{\circ} \mathrm{C} /$ min. Dimensional change at the casting temperature was registered as the thermal expansion value (\%). Three measurements for each condition were performed.

\section{Compressive strength}

Freshly mixed investment was poured into a brass mold (10 $\mathrm{mm}$ in diameter and $20 \mathrm{~mm}$ in length). The set specimen was removed from the mold 25 minutes after the start of mixing and kept in a container with a $100 \%$ relative humidity. Green strengths of the investments were obtained by a compression test at 30 and 40 minutes after the start of mixing. Fired strengths of the investments after QHM and CHM were also obtained. Tests were conducted using a universal test machine (AG-1000E, Shimadzu, Kyoto, Japan) at a cross-head speed of $0.5 \mathrm{~mm} / \mathrm{min}$. The six specimens were measured for each condition.

\section{Dimensional accuracy of casting}

A crown-type wax pattern was prepared using inlay wax (Inlay wax medium, GC, Tokyo, Japan) (Fig. 1).

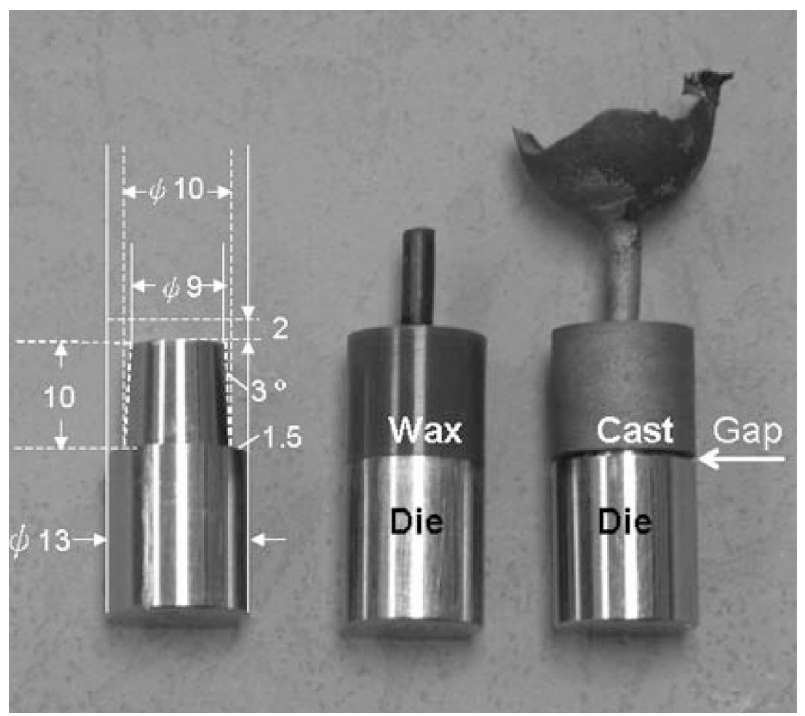

Fig. 1 Mold and diagram of wax pattern (unit: $\mathrm{mm}$ ).

Table 1 Investments used and characteristics expressed by the manufacturers

\begin{tabular}{cccccccc}
\hline Brand & Manufacturer & Code & $\begin{array}{c}\text { Batch } \\
\text { No. }\end{array}$ & $\begin{array}{c}\text { Concentration of } \\
\text { mixing liquid }\end{array}$ & L/P & $\begin{array}{c}\text { Setting } \\
\text { expansion }(\%)\end{array}$ & $\begin{array}{c}\text { Thermal } \\
\text { expansion* }\end{array}$ \\
\hline Tancovest & Bego & TV & $-\quad \begin{array}{c}80 \% \text { Bego Sol: } \\
20 \% \text { distilled water }\end{array}$ & 0.20 & 0.20 & 0.64 \\
Rematitan plus & Dentaurum & RT & 20268 & $\begin{array}{c}100 \% \text { Rematitan } \\
\text { plus liquid }\end{array}$ & 0.16 & 0.34 & 0.54 \\
\hline
\end{tabular}

\footnotetext{
*: At casting temperature
} 
The taper of the axial plane of the master stainless steel die (E-003, Seiki, Tokyo, Japan) was 1/10 (30), and the shoulder preparation margin was $1.5 \mathrm{~mm}$. At 24 hours after the wax pattern preparation, the gap between the wax pattern and metal die (DW) at three points were measured using a profile projector (PJ-2500, Mitsutoyo, Tokyo, Japan).

The wax patterns were then set up in the center of a metal ring $(30 \mathrm{~mm}$ in diameter and $40 \mathrm{~mm}$ in height) lined with one fold of the $0.7-\mathrm{mm}$ thick ring liner sheet, and with a sprue $3.0 \mathrm{~mm}$ in diameter. The distance between wax pattern and the edge of the casting ring was $10 \mathrm{~mm}$ for RT and $5 \mathrm{~mm} \mathrm{TV}$. Then the wax patterns were embedded and heated in the aforementioned manner. Five titanium castings of each casting condition were obtained from a commercially pure titanium ingot (Titanium A, $10 \mathrm{~g}$, Morita, Osaka, Japan) using an argon arc melting and gas pressure casting machine (Cyclarc II, Morita, Osaka, Japan). The casting was cooled to room temperature and removed from the mold, it was sandblasted with $50-\mu \mathrm{m}$ alumina at a pressure of $0.4 \mathrm{MPa}$ for five seconds. The casting was ultrasonically cleaned in distilled water. Gap between the casting and the metal die (DC) was then measured using a profile projector.

The dimensional accuracy of titanium casting (D) was determined by the discrepancy between the gap of the wax pattern and that of the casting, as expressed in the following formula:

$$
\begin{aligned}
& -\mathrm{D}(\%)=[(\Delta \mathrm{d} \times 1 / 10) / 10] \times 100 \% \\
& \Delta \mathrm{d}=\mathrm{DW}-\mathrm{DC}
\end{aligned}
$$

In addition, the internal structure of the two molds was also observed with a field emission scanning electron microscope (JSM-6700F, JOEL, Tokyo, Japan).

\section{Micro Vickers hardness}

The sprue of the casting for dimensional accuracy measurement was embedded in an acrylic resins and sectioned using a low-speed diamond saw with a water coolant. The sectioned surface was consecutively polished with 220-, 400-, 600-, 800-, 1000-, 1200-, and 1500-grit silicone carbide papers under running water.

Vickers hardness (Hv) of the casting was measured from 50 to $500 \mu \mathrm{m}$ in depth from the surface using a micro Vickers hardness tester (HMV-2000,
Shimadzu, Kyoto, Japan) under a load of $0.98 \mathrm{~N}$ and a duration time of 15 seconds. Five titanium castings from each casting condition were examined.

\section{Surface roughness}

Three full crown castings from each condition were sectioned into two parts along the occlusogingival axis of the crown using a high-speed abrasive wheel saw with a water coolant. The surface roughness value ( $\mathrm{Ra}$ ) of each crown casting was determined using a surface analyzer (Surfcom 50A, Tokyo Seimitsu, Tokyo, Japan) with a traverse length of $2.4 \mathrm{~mm}$ and a cut-off length of $0.8 \mathrm{~mm}$ at three measuring locations: outer and inner proximal surfaces, as well as the outer occlusal surface. For each test location of the crown, three measurements were obtained and the mean value of these three measurements was used for calculation.

\section{Statistical analysis}

Setting and thermal expansions, green and fired strengths, and accuracy of the casting were analyzed with two-way ANOVA and Tukey-Kramer comparison. Three-way ANOVA and Tukey-Kramer comparison were used for the statistical evaluation of Vickers hardness and surface roughness. Statistical calculations were performed using statistical software (JMPIN 5, Cary, NC, USA) $(\mathrm{p}<0.05)$.

\section{RESULTS}

\section{Setting expansion}

Setting expansion values of both investments at 30 , 40 , and 120 minutes after the start of mixing are summarized in Table 2. The setting expansion commenced at 3 (RT) and 5 (TV) minutes, and the maximum expansion of $\mathrm{RT}$ and $\mathrm{TV}$ were observed at 5 and 15 minutes after the start of mixing, respectively. A slight decrease was shown after the maximum expansion. The setting expansion of RT was significantly greater than that of $\mathrm{TV}$, regardless of measuring period.

\section{Thermal expansion}

Typical thermal expansion curves are shown in Fig. 2. With $\mathrm{TV}$, rapid expansions at 250 to $300^{\circ} \mathrm{C}$ and 550 to $600{ }^{\circ} \mathrm{C}$ were due to transformation of cristobalite and quartz, respectively. With $\mathrm{RT}$, only the expansion at 550 to $600^{\circ} \mathrm{C}$ was detected. At the

Table 2 Results of setting expansion, thermal expansion, and total expansion of investments

\begin{tabular}{ccccccccc}
\hline \multirow{2}{*}{ Code } & \multicolumn{3}{c}{ Setting expansion (\%) } & \multicolumn{2}{c}{ Thermal expansion (\%) } & \multicolumn{3}{c}{ Total expansion (\%) } \\
& $30 \mathrm{~min}$ & $40 \mathrm{~min}$ & $120 \mathrm{~min}$ & QHM & CHM & QHM & CHM \\
\hline TV & $0.11(0.04)$ & $0.10(0.04)$ & $0.10(0.04)$ & $0.64(0.06)$ & $0.76(0.07)$ & 0.75 & 0.86 \\
RT & $0.57(0.08)$ & $0.56(0.08)$ & $0.56(0.08)$ & $0.39(0.09)$ & $0.34(0.09)$ & 0.96 & 0.90 \\
\hline \multicolumn{2}{l}{ QHM: quick heating method; CHM: conventional heating method } & & &
\end{tabular}


casting temperature, the thermal expansions of TV after CHM and QHM were $0.76 \%$ and $0.64 \%$, respectively. As shown in Table 2, the thermal expansion of RT was significantly lower than that of TV re-

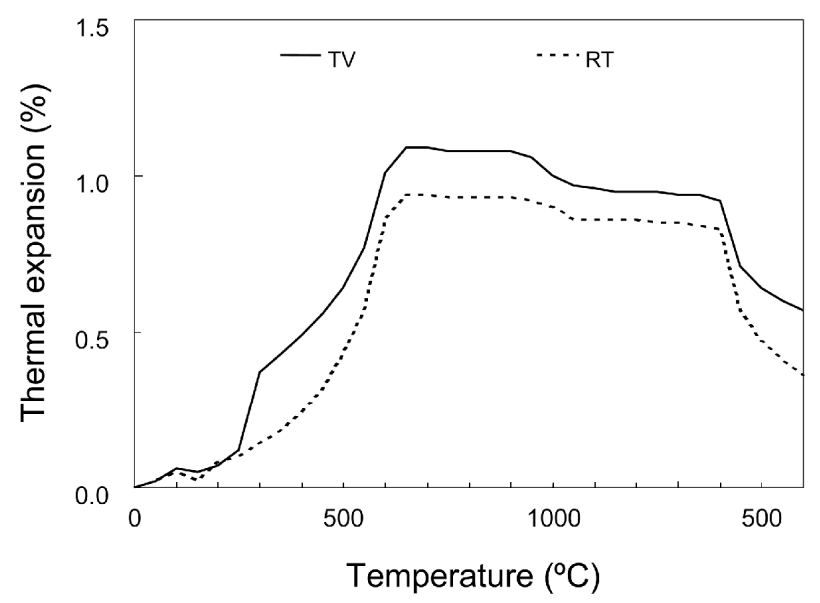

Fig. 2 Thermal expansion curves of both investments with quick heating. gardless of heating method.

\section{Compressive strength}

Compressive strengths are shown in Table 3. The green strengths at $40 \mathrm{~min}$ were significantly greater than those at $30 \mathrm{~min}(\mathrm{p}<0.05)$. In particular, the green strengths of $\mathrm{TV}$ were significantly smaller than those of RT, but the fired strengths of TV were significantly greater than those of RT. In terms of the fired strength, those of QHM were greater than those of CHM, though the differences were not significant.

\section{Dimensional accuracy of casting}

The dimensional accuracy results of the castings are summarized in Table 3 whereby negative values were yielded. According to two-way ANOVA, both heating method and investment did not significantly affect the dimensional accuracy of the castings.

Fig. 3 shows the SEM images of the internal structure of both molds after firing. It could be seen that TV contained more small particles and had less porosity than $\mathrm{RT}$.

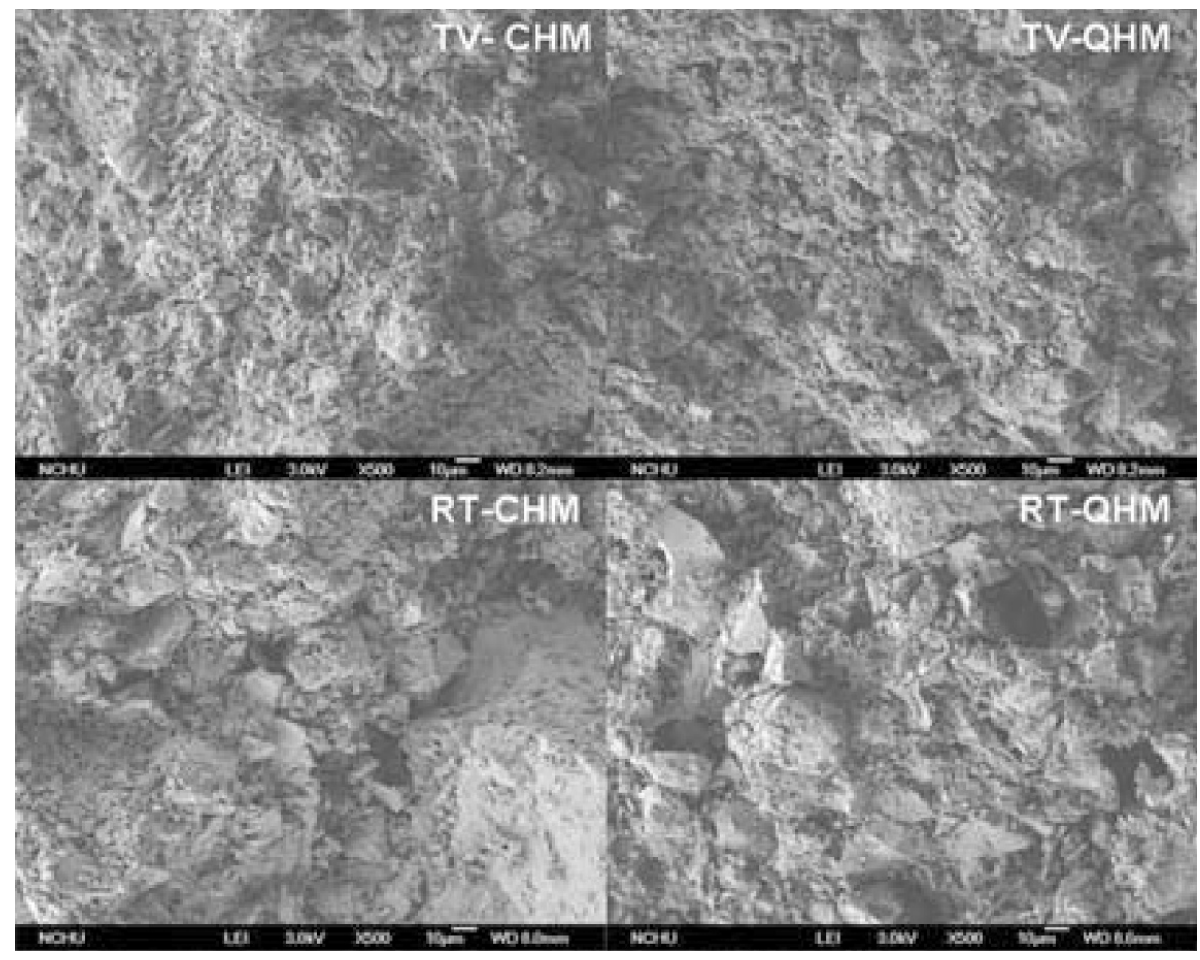

Fig. 3 SEM images of the internal structure of two molds after firing.

Table 3 Results of the compressive strength of investments and dimensional accuracy of Ti castings

\begin{tabular}{cccccccc}
\hline \multirow{2}{*}{ Code } & \multicolumn{2}{c}{ Green strength $(\mathrm{MPa})$} & \multicolumn{2}{c}{ Fired strength $(\mathrm{MPa})$} & \multicolumn{2}{c}{ Dimensional accuracy (\%) } \\
& $30 \mathrm{~min}$ & $40 \mathrm{~min}$ & $\mathrm{QHM}$ & $\mathrm{CHM}$ & QHM & CHM \\
\hline $\mathrm{TV}$ & $4.4(0.57)$ & $7.7(0.43)$ & $17.6(1.55)$ & $15.6(1.46)$ & $-0.57(0.10)$ & $-0.58(0.15)$ \\
$\mathrm{RT}$ & $10.3(1.43)$ & $12.2(1.36)$ & $13.8(1.67)$ & $13.2(1.44)$ & $-0.57(0.16)$ & $-0.61(0.14)$ \\
\hline \multicolumn{2}{l}{ QHM: quick heating } & method; CHM: conventional heating method & & &
\end{tabular}




\section{Micro Vickers hardness}

Fig. 4 shows the micro Vickers hardness of the castings. The Vickers hardness (Hv) at a depth of 50 to $500 \mu \mathrm{m}$ from the specimen surface of the RT investment ranged from 191 to 557; as for TV, it ranged from 169 to 490. Three-way ANOVA revealed that the investment, the depth of measurement, and the interaction between the investment and the depth of measurement were significant. However, the heating method and the other interactions were not significant. As the measuring point deepened, the Vickers hardness decreased. Nonetheless, no significant differences were found among the Hvs at measuring points 200 to $500 \mu \mathrm{m}$ from the specimen surface. The Hvs of RT were greater than those of TV especially at the shallow measuring points. At deep measuring points, the Hvs were not significantly different regardless of the investments or the depth of measurements.

\section{Surface roughness}

Fig. 5 shows the obtained surface roughness of the castings. Three-way ANOVA revealed that the investment and measuring location were significant, while the heating method and all interactions were insignificant. The Ras of TV were significantly greater than those of $\mathrm{RT}$, and that the $\mathrm{Ra}$ of the occlusal surface was significantly greater than those of the approximal surfaces. It should also be noted that the Ras values were not significantly influenced by the heating method.

\section{DISCUSSION}

Several types of binding systems are now available for titanium casting investments. A previous study 18) suggested the possible use of the quick heating method with selected silica- and alumina-based phosphate-bonded investments. The characteristics of commercial phosphate-bonded investments for quick heating have been reported to be similar to those for conventional heating except for the absence of carbon powder ${ }^{13)}$. In the present study, the examined silicaand alumina-based phosphate-bonded investments for titanium did not contain carbon powder. The green strengths of examined investments at $30 \mathrm{~min}$ were more than 4.4 $\mathrm{MPa}$ which was greater than those of conventional phosphate-bonded investments for conventional heating ${ }^{12,13)}$, and also equal to or greater than those of conventional phosphate-bonded investments for quick heating ${ }^{12,13)}$. In terms of thermal expansion, those of the examined investments in this

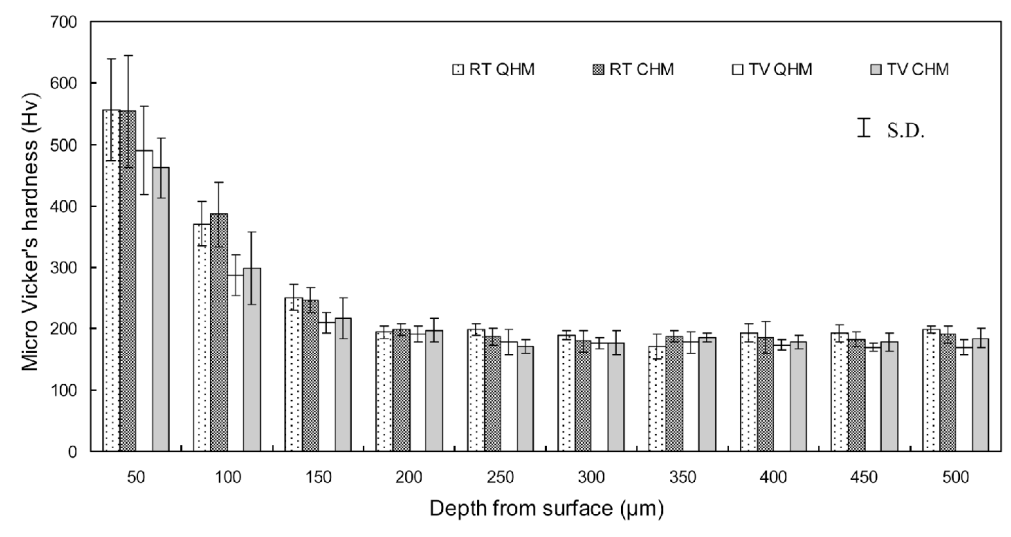

Fig. 4 Vickers hardness of each Ti casting in cross-section.

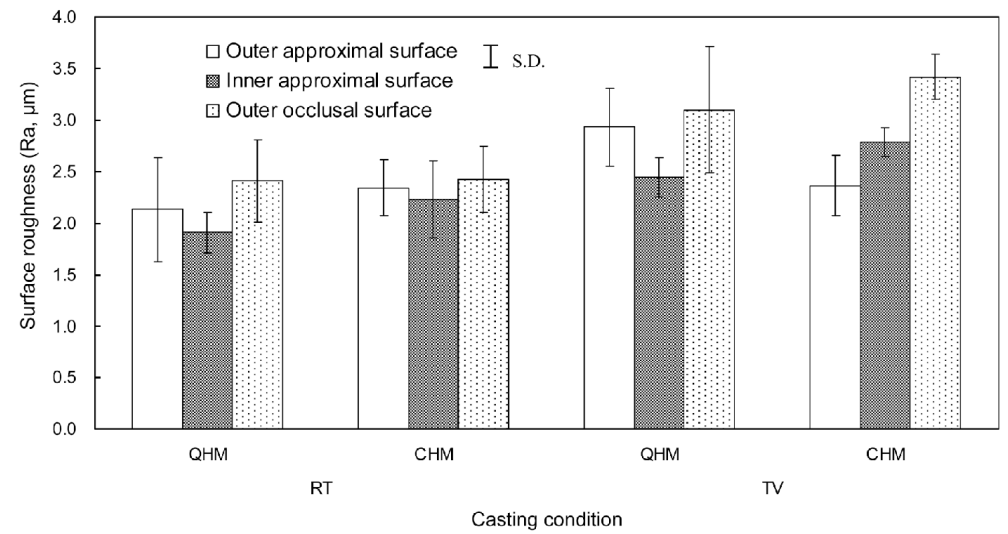

Fig. 5 Surface roughness of Ti casting at each location. 
study did not cause any rapid dimensional change during heating and cooling, which was similar to that observed in previous reports ${ }^{12,13)}$. As for the fired strengths of examined investments after quick heating, they were significantly greater than those after conventional heating but generally greater than those of previously reported conventional phosphatebonded investments ${ }^{13)}$. In view of the results obtained in this study, it could be concluded that the examined investments could be used for quick heating.

However, a sound casting using TV could not be obtained when the wax pattern was located $10 \mathrm{~mm}$ from the edge of the casting ring in our preliminary study. Sound castings from TV were obtained by changing the wax location from $10 \mathrm{~mm}$ to $5 \mathrm{~mm}$ from the edge of the casting ring. The main difference of these two locations was the thickness of the investment from the wax pattern. A thin investment layer could have allowed evaporated water or wax during heating to pass through easily. SEM images of TV (Fig. 3) suggested that this investment contained a greater number of small particles and might have less permeability than RT. Harun-Urashid et al. ${ }^{19)}$ reported that application of a titanium casting with quick heating was successful when the mold was preheated to remove water and wax. These results indicated the importance of permeability of investments for quick heating.

Expansions of the investment during setting and heating generally compensate casting shrinkage. A small setting expansion is desirable for accurate castings because a large setting expansion causes deformation of the wax pattern in a casting ring. The setting expansion of RT was smaller than the previously reported $0.70 \%{ }^{20}$ ) , but larger than the $0.34 \%$ expressed by the manufacturer. This discrepancy might be due to the different measurement methods employed, such as absence or presence of a ring liner, a magnitude of measurement force, and an expansion in a U-shaped brass trough or steel ring.

Thermal expansions of the examined investments were similar to conventional silica-based phosphatebonded investments containing quartz and cristobalite. However, the effect of heating rate on thermal expansion of investments for quick heating is debatably varied among researchers; some studies ${ }^{11,21,22)}$ reported that the quick heating method reduced thermal expansion, one study ${ }^{14)}$ claimed increases of thermal expansion, whereas some studies ${ }^{12,13)}$ indicated no influence at all. The thermal expansion of phosphatebonded investments occurs mainly due to the transformation of silica. Therefore, quick heating would have a small effect on thermal expansion if the setting expansion of the phosphate investment is completely accomplished. In this study, the setting expansion was completely accomplished before the investment was heated. As a result, heating method exerted only a slight influence on thermal expansion.

Dimensional accuracy did not vary with heating method which was in agreement with previous reports ${ }^{17,23,24)}$. The total expansion at the casting temperature calculated as a sum of setting expansion and thermal expansions is generally useful to predict dimensional accuracies. In this study, the total expansions with conventional and quick heating methods of TV were 0.86 and $0.75 \%$, respectively; those of $\mathrm{RT}$ were 0.90 and $0.96 \%$, respectively. It was reported that casting shrinkage of titanium castings ranged from 1.8 to $2.0 \%{ }^{25)}$. Moreover, it was also reported that full coverage-type crown castings of a thick shoulder margin tended to show a relatively greater marginal discrepancy ${ }^{26)}$. In the light of these findings, total expansion is thus not suitable for predicting accuracy of titanium castings ${ }^{9)}$. Against this background, further research is necessary to obtain a casting of similar size to the wax pattern for prosthetic restorations.

Due to reaction between molten titanium and the investment at high temperatures, a hard layer is formed on the external surface of titanium. The thick titanium oxide layer increases the hardness but decreases the mechanical properties of titanium. In the present study, the thickness of the hardened surface layer was approximately $200 \mu \mathrm{m}$, which was slightly thicker than a previously reported value ${ }^{18)}$. This difference in thickness might be caused by the elements of the investments. It should be noted that the heating method did not affect the reaction layer thickness. This was because both investment elements and temperature were not different for both heating methods.

Previous studies suggested that numerous factors such as alloy type, location in the mold, the mold and casting temperatures, and sandblast method influence the surface condition of the castings ${ }^{5,27)}$. In the present study, the mold temperatures at casting with QHM and CHM were according to the manufacturers' suggestions. In addition, with QHM, the mold was fired directly at the elevated temperature after a shorter setting time. Nonetheless, the investments developed sufficient compressive strength. Our results agreed with a previous report ${ }^{23)}$ that there were no significant differences in the surface roughness values of the castings made either with the quick heating or the conventional heating method. Indeed, the Ra values of $\mathrm{RT}$ and $\mathrm{TV}$ castings were $1.91-2.43 \mu \mathrm{m}$ and $2.37-3.42 \mu \mathrm{m}$, respectively, which were similar to or larger than those of previous studies $(1.63-2.50 \mu \mathrm{m})$ using conventional casting processing ${ }^{6,9,28)}$. When compared to gold alloy casting using phosphate-bonded investments with the quick heating method, the surface roughness of titanium castings in this study was similar to or slightly larger than that of gold alloy which ranged from 1.25 to $2.98 \mu \mathrm{m}^{22,23)}$. The reason for this differ- 
ence in the surface roughness could be due to the investment material and reaction layer. In the present study, the occlusal surface of the titanium casting had higher Ra than those at proximal surfaces. The initial solidification of molten titanium could occur at the margin and proximal walls of the crown after casting. In contrast, the solidification on the occlusal surface of the crown was delayed. Consequently, the occlusal surface of the crown showed a rougher surface than the proximal surfaces.

The resulting characteristics of the two commercial silica-phosphate-bonded investments for titanium were deemed acceptable after processing with the quick heating method. Assessment of the dimensional accuracy of crowns cast in conventional silicabased investment was difficult due to the reaction of titanium with the mold. The reaction layer of silicabased phosphate-bonded investment for titanium was relatively thick compared with magnesia-, calcia-, and alumina-based investments. To reduce reaction layer thickness, a new investment with a more stable refractory, such as magnesia, calcia and alumina, for the quick heating method would need to be further investigated.

\section{CONCLUSION}

In the present study, the following properties were obtained from the examined investments for titanium with quick heating method: sufficient compressive strength, as well as similar setting and thermal expansion values as those with conventional heating method. Castings obtained using the quick heating method were slightly smaller compared to their corresponding wax patterns, and thickness of the reaction layer was approximately $200 \mu \mathrm{m}$. Further, the heating method did not significantly influence either the dimensional accuracy or surface roughness of the titanium castings. These results suggested that the examined commercial investments for titanium could be used with the quick heating method.

\section{ACKNOWLEDGEMENTS}

The study was supported in part by a grant from the National Science Council of Taiwan (NSC 90-2213E-040-003).

\section{REFERENCES}

1) $\mathrm{ADA}$ Council on Scientific Affairs. Titanium applications in dentistry. J Am Dent Assoc 2003; 134: 347-349.

2) Kobayashi E, Wang TJ, Doi H, Yoneyama T, Hamanaka H. Mechanical properties and corrosion resistance of Ti-6Al-7Nb alloy dental castings. J Mater Sci Mater Med 1998; 9: 567-574.

3) Sato H, Komatsu M, Miller B, Shimizu H, Fujii H, Okabe T. Mold filling and microhardness of $1 \% \mathrm{Fe}$ ti- tanium alloys. Dent Mater J 2004; 23: 211-217.

4) Yan M, Takahashi H. Gypsum-bonded alumina dental investment for high-fusing casting. Dent Mater J 1998; 17: $174-185$

5) Meng Y, Nakai A, Goto S, Ogura H. Study of resinbonded calcia investment. Part 3: Hardness of titanium castings. Dent Mater J 2004; 23: 46-52.

6) Takahashi J, Kitahara K, Kubo F. Phosphate-bonded $\mathrm{ZrSiO}_{4}$ investments added with $\mathrm{ZrC}$ and $\mathrm{ZrN}$ for casting titanium. Dent Mater J 2004; 23: 314-320.

7) Kikuchi H, Onouchi M, Miyanaga K, Wakashima M, Okuno O, Nishiyama M. The thickness effects of titanium castings on the surface reaction layer. Dent Mater J 2004; 23: 387-394.

8) Hung CC, Hou GL, Tsai CC, Huang CC. Pure titanium casting into zirconia-modified magnesia-based investment molds. Dent Mater 2004; 20: 846-851.

9) Yan M, Takahashi H, Nishimura F. Dimensional accuracy and surface property of titanium casting using gypsum-bonded alumina investment. Dent Mater J 2004; 23: 539-544.

10) Kitahara K, Kubo F, Takahashi J. Thermal expansion typed investments for casting titanium. Dent Mater J 2004; 23: 1-7.

11) Takahashi H, Nakamura $H$, Iwasaki $N$, Habu $N$, Ishiwata M, Nishimura F. Properties of commercial gypsum-bonded dental investments for quick heating. J J Dent Mater 1993; 12: 714-723.

12) Habu N, Takahashi H, Yan M, Motomura K, Nakamura H, Nishimura F. Properties of a phosphatebonded dental investment for quick heating. J J Dent Mater 1995; 14: 681-690.

13) Yan M, Takahashi H, Nishimura F, Habu $N$, Nakamura H, Motomura K. Comparsion of properties of phosphate-bonded investments for quick heating. J J Dent Mater 1997; 16: 405-414.

14) Takahashi H, Nakamura $H$, Habu $N$, Ohtani $N$, Iwasaki N, Yahagi M, Nishimura F. Properties of gypsum-bonded investment for quick heating of 20-minute type. J J Dent Mater 2000; 19: 77-83.

15) Mori T, Aghajani F. Gypsum-bonded investment and dental precision casting (II) Investment for the quick casting technique. Dent Mater J 2003; 22: 521-31.

16) Mori T, Aghajani F. Gypsum-bonded investment and dental precision casting (III) Composition of investment for the quick casting technique. Dent Mater J 2004; 23: 230-232.

17) Takahashi $H$, Nakamura $H$, Iwasaki $N$, Morita $N$, Habu N, Nishimura F. Variables effecting casting accuracy of quick heating casting investments. J Stomatol Soc Jpn 1994; 61: 242-249.

18) Tonami K, Ohtani T, Iwasaki N, Motomura $K$, Nakamura H, Takahashi H, Nishimura F. Mechanical properties of titanium casting obtained using shorttime cast procedure. J Stomatol Soc Jpn 1998; 65: 344348.

19) Harun-Urashid QM, Tamaki Y, Zhang ZT, Ozawa A, Miyazaki T, Shimakura M. Labor reduction for mold preparation of a commercial titanium cast denture system using a heat-shock method. Dent Mater J 2000; 
19: 413-421.

20) Soo S, Palmer R, Curtis RV. Measurement of the setting and thermal expansion of dental investments used for superplastic forming of dental implant superstructures. Dent Mater 2001; 17: 247-252.

21) Papadopoulos T, Axelsson M. Influence of heating rate in thermal expansion of dental phosphate-bonded investment material. Scand J Dent Res 1990; 98: 60-65.

22) Blackman RB. Evaluation of the dimensional changes and surface roughness of gold crowns cast with rapidly prepared phosphate-bonded investment: A pilot study. J Prosthet Dent 2000; 83: 187-193.

23) Konstantoulakis E, Nakajima H, Woody RD, Miller AW. Marginal fit and surface roughness of crowns made with an accelerated casting technique. J Prosthet Dent 1998; 80: 337-345.

24) Schilling ER, Miller BH, Woody RD, Miller AW, Nunn
ME. Marginal gap of crowns made with a phosphatebonded investment and accelerated casting method. J Prosthet Dent 1999; 81: 129-134.

25) Nishimura F, Watari F, Nakamura H, Fukumoto R, Morita N. Casting accuracy and shrinkage of titanium casting made with zirconia investment. J J Dent Mater 1990; 9: 850-857.

26) Ohno T, Kuroiwa A. Effect of differences in fabrication methods for pure titanium crown restoration on fitness. J J Dent Mater 2001; 20: 287-299.

27) Ogura H, Asgar K. Inner surface roughness of complete cast crowns made by centrifugal casting machines. J Prosthet Dent 1981; 45: 529-535.

28) Hattori M, Hasegawa K, Yoshinari M, Kawada E, Oda $\mathrm{Y}$, Okabe T. Casting accuracy of experimental Ti- $\mathrm{Cu}$ alloys. Dent Mater J 2001; 20: 16-23. 